\title{
HOUSEHOLD/INDIVIDUALS IN THE PROCESS OF PRODUCTION AND DELIVERY OF ELECTRICITY FROM RENEWABLE ENERGY SOURCES - PHOTOVOLTAIC SYSTEMS
}

\author{
Serjoza Markov ${ }^{1}$
}

DOI: https://doi.org/10.31410/ITEMA.2020.267

\begin{abstract}
First and foremost, the main inspiration for the specific problematics in this paper is solar energy as clean and profitable energy for businesses in the Republic of North Macedonia.

The question that arises as the basis is finding the reason why the progress in the sector of renewable energy sources in this country is still slow and insufficient.

The results and conclusions of the research shall be achieved via comprehensive analysis, and by finding the answer to the posed question through the: theoretical analysis, the inductive and deductive methods, as well as description shall be used, whereas the techniques utilized shall be questionnaires, interviews, observations.

By summarizing in one place all the theoretical and empirical aspects, we are finding the answer to the main question asked: One of the possible reasons for this actual situation is the fact that so far there is no possibility in this country for individuals to be involved in the process of production and transmission of electricity in the energy system.

The goal is achieved in this paper through providing specific guidelines and suggestions regarding the improvement of the legal framework in the Republic of North Macedonia, emphasizing on benefits if the households are allowed to deliver their produced solar energy and considering the possible ways to remove the determined obstacles for implementing this idea.,
\end{abstract}

Keywords: Electricity, Solar energy, Republic of North Macedonia.

\section{INTRODUCTION}

$\mathrm{S}$ olar energy is clean and profitable for businesses in R.N. Macedonia. Our country has more than 280 sunny days a year and the production of one photovoltaic can reach 1500 $\mathrm{kWh}$ per year, which is far above the European average.

This is followed by the capacities that Macedonia has, hence according to the Low carbon energy calculator ${ }^{2}$ for 2050 , Macedonia, in 2050, can be supplied with electricity from fully decarbonized sources, almost $60 \%$ of solar energy.

South East Europe Sustainable Energy Policy (SEE SEP) is a multi-annual program funded by the European Commission that provides a technical analysis explaining the critical pathways described in the 2050 Low Carbon Energy Calculator for South East Europe, a decision-making tool developing technical and economic scenarios for the future of the decarbonization of the energy sector in this region.

Law Company Cukic \& Markov, 33A-01 Aminta Treti str., 1000 Skopje, Republic of North Macedonia

For complete calculator and web tool, please visit: http://www.see2050carboncalculator.net 
The technical analysis of the SEE SEP - 'Southeast Europe: The Road to the EU or the Road to Nowhere? Energy Plan for 2050', using the Calculator and expert opinions, predicts two scenarios and includes 'sliders' for the development of changes in various economic sectors to obtain results by $2050^{3}$.

The roadmaps follow the first scenario focused on future planned coal developments and the second scenario 'Road to the EU' where the countries of Southeast Europe (including R.N. Macedonia) successfully operate in accordance with the EU regulations on environment and climate change.

In R.N. Macedonia, although there is evident progress in the sector of renewable energy sources, it is still slow and insufficient, and one of the possible reasons for that is the fact that so far there is no possibility for individuals to be involved in the process of production and transmission of electricity in the energy system.

Although so far in our country there were several initiatives from different social actors, institutions, and similar, still this idea for active involvement in the production from photovoltaic systems and delivery/sale of such electricity by individuals, has not been realized in practice, nor were made changes in such direction in the last Law on energy. Unlike the individuals, the legal entities have different treatment and the same according to the applicable $\mathrm{law}^{4}$ in the practice can be actively included, besides in the production at the same time also in the delivery/sale of the produced solar energy through a premiums model and preferential tariffs model.

\section{POSSIBLE WAYS AND METHODS OF TREATMENT AND BENEFITS FOR USING THE 'SURPLUS' ELECTRICITY PRODUCED BY HOUSEHOLDS FROM PHOTOVOLTAIC SYSTEMS IN ACCORDANCE WITH THE PERFORMED ANALYSIS ${ }^{5}$}

Namely, as a possible way to stimulate such development is the very idea that individuals without starting a company to be able to produce electricity from renewable energy sources and deliver it directly to the system with the possibility of 'settlement' with the electricity distributor.

Encouraging and activating the households to use the renewable energy sources could be expected, if they are allowed in case they install, for example, photovoltaic panels, the electricity, in addition to being able to use it for their own needs, to be able to hand it over to a previously concluded contract to the operator/distributor or to sell it directly on the electricity market.

Hence, it is necessary to find an appropriate applicable mechanism by which the surplus, which was especially incurred by the producer, is regulated in a way that everyone would have benefit,

3 Dominković, D. F., Bačeković, I., Ćosić, B., Krajačić, G., Pukšec, T., Duić, N., \& Markovska, N. (2016). Zero carbon energy system of South East Europe in 2050. Applied Energy

4 Law on energy 'Official Gazette of the Republic of Macedonia' No.96/2018, 96/2019

5 ، Grid measurement in the Republic of Macedonia, possibilities, perspectives, examples-how to cleaner energy?" by Sonja Risteska, Analytica Think Tank, February, 2017. Before passing the last Law on energy, 'Analytica' participated with initiative the individuals to be allowed without starting a company to be authorized producers and sellers of renewable sources electricity. (http://www.analyticamk.org/images/2017/mrezno_merenje_a40ba.pdf) 
both distributors and suppliers, as well as the households themselves that are in the role of producers.

\subsection{Comparative analysis of applicable ways and methods for stimulating the production and delivery of solar energy from households and feeding (preferential) tariffs}

There are several ways and methods used in Europe and America through which the production and transmission of solar energy from households to the energy system are allowed, encouraged, and stimulated.

These good and functional examples could find appropriate application in our country if the same make sufficient efforts to overcome some already located obstacles, which the institutions in the energy field refer to and use them as an excuse for the current situation.

Available options are the introduction of monthly, seasonal, annual, or kWh-credits indefinitely from the unspent solar energy produced by households.

It is necessary to enable the users-individuals who produce their solar energy to be able to use it at any time, and not only when it is generated (alternating/ depending on the weather conditions). In such a way, on a monthly basis, the users are enabled to use at night the solar energy produced during the day.

On an annual basis, the net kilowatt credit is shifting, allowing households to use solar energy, which, for example, was produced in July and delivered to the system, in December.

A similar practice would exist with the periodic grid measurement (for example, every 6 months/one year).

What is also proposed and necessary, and which is already functioning in other European countries, is the possibility for the household as a producer and consumer of solar energy to hand over in the system the excessed electricity that it cannot use and, at the same time, to get a credit on the bill that will be applied in terms of future electricity consumption.

Vice versa, if the household-consumer spent more than what was delivered to the system, then, it would pay the same price as any other consumer (retail price / price of electricity for households).

While, if the household manages to save the consumption, another option is in the case on the date of the anniversary when the offset of spent/handed over there are excess production credits left on the bill, the distribution company to be able to repay that credit at market (current price per MWh on the open market) or at retail price, which depends on how this issue would be regulated by law.

The idea is based on purely economic motives, but also on environmental benefits, and the point is to first satisfy its own consumption, and only then to 'bring back' to the system.

This method can be defined as a collection mechanism that rewards individuals / owners of the photovoltaic panels for the electricity they supply to the grid.

For example, if a household has a photovoltaic panel on the roof and is able to generate more electricity than the household can use during the day and has built-in so-called smart two-way meter that will turn backwards, would provide credits when the household consumes electricity 
overnight or other periods when the electricity consumption exceeds the one which comes out from the system.

In that case, the households would be billed only for their 'grid' use of the energy.

Another possible similar option is at the end of the billing period, if the electricity produced by the photovoltaic system exceeds the consumption at the place of production based on the agreement with the distributor, for the difference in the produced energy the household to get credit, by which the electricity bill will be reduced, with the equivalent amount the next time.

Of course, in such options, the household must use a two-way electricity meter that measures changes in the electricity flow, which means that it measures the consumption of electricity (taken from the grid) and the amount of electricity delivered to the grid (produced by the household).

A very specific example, which has been operating for a long time in California ${ }^{6}$, is the use of energy by the user, which is determined by dynamics prices according to the function of the purchase price of electricity. In this case the users' meters are programmed remotely to calculate and read the value.

So, there can be a variable calculation of the prices of the excess energy produced by the system according to this example for calculation at market price.

This way allows small systems to have zero annual net cost, if the consumer can switch to a low-cost tariff while the electricity generation is at its peak then back to the grid, and not used locally.

When electricity generation exceeds customer demand, excess power generation automatically goes through the smart meter back into the grid by measuring "backwards" in order to be able to credit the household bill.

At other times of the day, when household demand may be higher than what it produced, it relies on additional quantities it takes from the grid.

The producers who have produced a net surplus of energy at the end of the twelve months can receive payment for this energy under special utility tariffs.

When it comes to net payment in European countries, within the payments two models are used for the payment of subsidies.

One of them is for the produced electricity, which is consumed at the place of production, and the other for part of the produced electricity that is delivered to the grid.

The first model pays a premium for real-time electricity consumption, such as the Italian model $^{7}$, while the other is an integrated model applied in Germany. In Italy the received credits

Grid measurement in California (http://www.gosolarcalifornia.ca.gov/solar_basics/net_metering.php) Ameli, N., Kammen, D.M. 2014. Innovations in financing that drive cost parity for long-term electricity sustainability: An assessment of Italy, Europe's fastest growing solar PVmarket. Energy for Sustainable Development, 19, 130-137. 
for the difference between the supplied/spent have no limit on use regardless of the electricity market fluctuations.

In this case, the households have an incentive to use their own produced energy because they would not benefit from the type of profit made, but only in the form of savings in electricity bills, which of course are significant.

\subsection{Feeding (preferential) tariffs}

Feeding (preferential) tariffs is a policy that encourages the production of electricity from renewable energy sources in a country, on a commercial level and promotes certain 'green' technologies.

The feeding tariff is also an energy-supply policy, which is focused on supporting the development of new renewable energy projects, offering producers long-term purchase agreements (guaranteed, always by the country) of the sold electricity ${ }^{8}$.

In the feeding tariff, which is an older applicable model in contrast to the previously considered options, it is specific that two electric meters are always needed.

\section{RENEWABLE ENERGY SOURCES EMPHASIZING THE PHOTOVOLTAIC SYSTEMS AND PARTICIPATION OF THE HOUSEHOLDS ACCORDING TO THE R.N. MACEDONIA'S REGULATION}

The applicable Law on energy ${ }^{9}$ in the R.N. Macedonia, among others, incorporates also the Directive 2009/28/EC for promoting the use of renewable sources of energy.

According to this law, a producer of electricity from renewable sources can acquire the status of a preferential producer of electricity from renewable sources, which gives him the right to use a premium or preferential tariff.

The law gives the preferential producer the right to use a premium or preferential tariff, in a manner and in a procedure prescribed by law, regulations and rules adopted based on this law and state aid regulations, according to which the Energy and Water Services Regulatory Commission ${ }^{10}$ is responsible for conducting and regulating the entire procedure.

The right to use a premium or preferential tariff is acquired through the application of procedures based on the principles of objectivity, transparency and non-discrimination.

A producer of electricity from renewable sources that are connected to the electricity distribution grid (meaning legal entities) can be represented on the electricity market by a virtual electricity producer.

The preferential producer that uses premium is selected by conducting a tender procedure with an auction for granting the right to use premiums for preferential producers.

\footnotetext{
$8 \quad$ NREL (National Renewable Energy Laboratory), A Policymaker's guide to feed-in tariff policy design, Technical report, July 2010, page 6 http://www.nrel.gov/docs/fy10osti/44849.pdf Law on energy 'Official Gazette of the Republic of Macedonia' No.96/2018, 96/2019 https://www.erc.org.mk
} 
An authorized producer who has acquired the right to use a premium for a certain power plant cannot use a preferential tariff and has not guaranteed the purchase of the produced energy for the same power plant by the electricity market operator.

The law defines the 'premium' as a form of financial support granted to a preferential producer of electricity from renewable sources as an additional amount to the price achieved by selling the produced energy on the electricity market.

'Preferred electricity producer' is defined as a producer of electricity from renewable sources that uses one of the support measures established by this law.

Although these two legal definitions do not clearly and decisively exclude individuals as possible preferential producers, still the bylaw and the manner of conceptualizing the use of the state measures allude to the impossibility of involving households in the transfer/sale of the energy produced from renewable sources.

This is evident from the definition of the term 'household', which according to the law represents a consumer connected to an energy distribution system, who supplies or produces energy for its own consumption in the household, but not for commercial or professional purposes.

In R.N. Macedonia are currently used these measures as an incentive to generate electricity from renewable energy sources and they are quite successful, although the quantities produced in these ways are far from the potential of the country.

\section{BENEFITS IF THE HOUSEHOLDS ARE ALLOWED TO DELIVER THEIR PRODUCED SOLAR ENERGY TO THE R. N. MACEDONIA'S ENERGY SYSTEM}

The benefits of allowing households to transmit their electricity to the system are huge, and the first and most important benefit is increased use of solar energy.

If R.N. Macedonia has the potential to produce 4.4. TWh in 2050, then the situation is clear, the citizens and the individual households must be more actively involved in using the solar potential that the state has.

Also, the second benefit is reduced pollution and participation in lower greenhouse gas emissions through the use of photovoltaic systems as renewable energy sources, and the third benefit is job creation and encouraging private investment.

'The next benefit is the increase in demand for solar energy systems, which in turn creates jobs for installers, electricians and manufacturers working in the solar supply chain', the analysis of 'Analytica Think-Tank' indicated ${ }^{11}$.

'The distributed solar systems can help avoiding significant investments in the infrastructure, reduce the pressure on state-owned fossil fuel-based electricity generation when demand is at its peak and at lower prices', the analysis said.

11 Grid measurement in the Republic of Macedonia, possibilities, perspectives, examples-how to cleaner energy?" by Sonja Risteska, Analytica Think Tank, February, 2017 
The idea of these models is to encourage self-sufficiency of energy needs as an independent entrepreneurial activity. The offset prescribed for independent generation and transmission of solar energy has the added advantage, by the fact that the investments in the distribution grid are more cost-effective than in the system with preferential tariffs. In this way, the awareness of fulfilling the obligations to increase the share of renewable energy sources in the total energy consumption for all, not only for the 'big' investors, would be further encouraged.

The increased awareness for rational use of electricity is also a benefit, as well as a lower load on the grid.

Another possible advantage of such system, emphasized in the same analysis, is that when the electricity market is fully open also for households, the electricity will be given to the buyer, to be offset at the end of the year; how much he spent from the grid, how much his own, and how much he gave in the system - and if he saved, such savings should be paid to him at a market price.

\section{OBSTACLES FOR INTRODUCING THE MODEL ALLOWING INDIVIDUALS TO GENERATE ELECTRICITY FROM PHOTOVOLTAIC SYSTEMS AND THE SURPLUS OF SOLAR ENERGY TO BE DIRECTLY DELIVERED IN THE ENERGY SYSTEM}

Although drastic changes may have been expected with the adoption of the latest Law on energy in the R.N. Macedonia, the role of households as potential producers and sellers of the produced solar energy remained unchanged. As potential obstacles for such condition, which are previously located by several energy institutions and companies in R.N. Macedonia according to the analysis ${ }^{12}$, the following can be pointed out.

\subsection{Costs for the consumers}

Expected is diversion of costs from consumers who use and sell solar energy to those who do not. In R.N. Macedonia the price for the feeding tariffs that are paid, is paid by the final consumers because it is included in their bills.

If they do not receive bills, in that case they would not pay grid fees, etc., so, the price for their use of the grid will have to fall to other users, which increases the price of electricity for end users. Hence, in adopting this measure, it is important to be introduced a payment of a grid fee and of the 'privileged' users-producers.

This would mean that the bills would be made in such way that the distributor would charge for the connection of the household to the grid, but not for the electricity delivered when the household uses its own generated electricity.

\subsection{Unprepared grid}

The lack of grid readiness remains a common critical point for integrating the solar energy in the grid.

\footnotetext{
12 ، Grid measurement in the Republic of Macedonia, possibilities, perspectives, examples-how to cleaner energy?" by Sonja Risteska, Analytica Think Tank, February, 2017, pp.23,24
} 
However, if there are significant investments in the electricity sector in the future as a result of the necessary upgrades, the proper investment and measures should ensure the integration of renewable energy sources and solve the problems with the alternation. The voltage failures of the grid and the return power in opposite direction could be a problem due to distributed solar panels. However, in some cases the studies have shown benefits from delayed investments in capacitor banks and resistive switches ${ }^{13}$. The distributed solar energy could even delay some upgrades of voltage regulator, gearbox load, and capacitor devices by providing voltage support and some kind of frequency regulation in combination with energy storage ${ }^{14}$.

\subsection{Technical shortcomings}

Technically, care must be taken on how will be performed the including of the households and the introduction of the model of 'settlement' of produced-delivered electricity, so that the electricity grid does not suffer from load. If the photovoltaic systems are in a location that is not yet well connected to the distribution grid, grid failures are possible and expected ${ }^{15}$.

\subsection{Calculation and including the Value Added Tax (VAT)}

A possible problem is the calculation of VAT, i.e. how it will be charged, if the price at which household buys electricity has VAT included, and the electricity that is delivered to the system; if it is calculated as purchase price, and not as retail, is not subject to VAT.

Hence, the problem is how to settle the delivered/spent, if VAT must be included when invoicing a bill.

\section{CONCLUSION}

With the drastic reduction of the price of solar and wind energy and the aging of the existing energy infrastructure in the region, R.N. Macedonia, as well as the whole of Southeast Europe faces the dilemma of whether to follow the path that relies exclusively on new coal development, without any significant progress in solar or wind energy, or to accept the challenge and advance towards EU accession using clean energy technologies and energy efficiency measures.

The price of solar panels is expected to decrease from around $6,6 € / \mathrm{W}$ in 2002 to $0.9 € / \mathrm{W}$ in $2027 .{ }^{16}$

Renewable sources in the electricity sector, inspiring new and innovative approaches, fundamentally change the policy and financial environment in terms of capacity expansion, shifting to lower marginal costs.

Generally, the investments in new electricity supplies will be crucial to meeting the EU Roadmap to reduce greenhouse gas emissions by $80 \%$ to the levels from 1990 until $2050 .{ }^{17}$

13 Gil, H. A., \& Joos, G. (2006). For quantification of the value of the delayed capacity to the grid of the distributed production. Power Systems, IEEE Transactions on, 21(4), 1592-1599

14 Southeast Europe: The Road to EU or the Road to nowhere? Energy plan for 2050: Technical analysis, 52

15 Sustavi poticanja za integrirane fotonaponske sustave, Andrea Brajko, Hrvatski operator tržišta energije d.o.o.

16 Cost overview for 2015 EUR. Zheng, C., \& Kammen, D. M. (2014). Innovative focused roadmap for a sustainable global photovoltaic industry. Energy Policy, 67, 159-169

17 SEE SEP, Southeast Europe: The Road to EU or the Road to nowhere? Energy plan for 2050: Technical analysis, 2016, 26 
Increasing the number of solar panels installed in the distribution system can also solve the issues with the supply system and the lack of electricity.

With the increasing presence of distributed solar energy, further grid upgrades can be expected to adapt to new technologies, as it is obvious that the grid needs upgrades for each new capacity. Second, the distribution company can improve its revenues, as well as monitor electricity, in parallel with the mentioned necessary investments in the grid and in the system.

This will enable future programs to satisfy the consumption or other forms of energy efficiency interventions to be able to effectively reshape both the electricity supply and consumption throughout the region ${ }^{18}$.

The roadmaps presented in the region can be contextualized within the global and European trends, emphasizing the reduction of the price of renewable energy sources, the ability for energy efficiency and renewable measures to create new jobs at a fast pace, and the possibility of integration by using the new grid architectures that can make Southeast Europe a leader, rather than lagging behind energy production and the deployment of technological infrastructure. ${ }^{19}$

Following up on this, the study ${ }^{20}$ demonstrated and established the hypothesis that although obstacles and problems such as reduced revenues for the country and distribution grid operators are expected, the risk of price increase for end users, and the need to upgrade the grid over time in order to receive such electricity; however, the practice shows that all these issues have answers, that citizens should be given the right to be responsible for the supply of electricity and to 'help' the system by supplying it with electricity at the peak.

The measure has been successfully implemented in the United States for decades, and is spreading across Europe, so with the inevitable liberalization of the electricity market, which should have happened until now, such measure will only be an added plus for households that have opportunities and would like to produce the electricity they use.

All this would mean that such investments are possible and desirable for the households and in accordance with the guidelines of the European Union, but of course, if proper development policies are created within the country itself.

18 SEE SEP, Southeast Europe: The Road to EU or the Road to nowhere? Energy plan for 2050: Technical analysis, 33

19 SEE SEP, Southeast Europe: The Road to EU or the Road to nowhere? Energy plan for 2050: Technical analysis, 52

20 ، Grid measurement in the Republic of Macedonia, possibilities, perspectives, examples-how to cleaner energy?" by Sonja Risteska, Analytica Think Tank, February, 2017, 33,34 